\title{
DIVERSIVIKASI PRODUK DAN EFISIENSI BISNIS DALAM KEBERLANJUTAN GREEN HOTEL PADA ERA NEW NORMAL DI HYATT REGENCY YOGYAKARTA
}

\author{
Heni Widyaningsih ${ }^{1}$, Hery Krestanto ${ }^{2}$, T. Prasetyo Hadi Atmoko ${ }^{3}$ \\ ${ }^{1}$ Akademi Pariwisata Yogyakarta, heni.widya08@gmail.com \\ ${ }^{2}$ Akademi Pariwisata Yogyakarta, herychrestanto@ymail.com \\ ${ }^{3}$ Akademi Pariwisata Yogyakarta, prasplg@gmail.com
}

\begin{abstract}
ABSTRAK
Dampak Covid 19 yang dirasakan dibidang perhotelan memaksa pihak hotel untuk melakukan hemat energi dan biaya. Penelitian ini bertujuan untuk mengetahui diversivikasi produk dan efisiensi bisnis dalam keberlanjutan green hotel pada era new normal di Hyatt Regency Yogyakarta. Penelitian ini menggunakan metode kualitatif dengan teknik pengumpulan data observasi, wawancara, dokumentasi dan study Pustaka. Keberlanjutan green hotel di hyatt Regency dilakukan dengan diversivikasi produk dan efisiensi bisnis. Diversivikasi produk di Hyatt Regency yaitu Merancang working space (Work From Hyatt), Summer camp untuk anak anak, walk the dog, menjual swimming poll untuk tamu di luar Hyatt. Diversivikasi produk tersebut dijalankan dengan ketentuan wajib mengkonsumsi food atau beverage di Hyatt Hotel minimal Rp. 100.000,- per peserta, Bekerjasma dengan grab wheels, konsep angkringan yang higienis, sehat, murah dan enak, serta melakukan efisiensi bisnis dengan menghemat energi listrik tanpa mengurangi pelayanan ke tamu dengan cara mengarahkan listrik kamar dengan gantungan kunci, sehingga jika tamu mengambil kartu kunci sebagian besar listrik peralatan akan mati secara otomatis, mengarahkan dispenser semua area, ke sakelar lampu, sehingga ketika mematikan lampu kantor akan otomatis mematikan dispenser, meminimalkan penggunaan kertas dan menggunakan kertas daur ulang, membangun kesadaran untuk program menabung energi melalui poster dan juga kampanye, menggunakan ecowasher untuk toilet, menggunakan lampu LED, menggunakan digital Thermostat, memasang pengatur waktu untuk penerangan area publik, memasang tab air otomatis di ruang makan karyawan, memasang pengatur waktu untuk instalasi pengolahan air limbah, menggunakan topside gas LPG Bulk, memasang arduino untuk mengatur pompa air portabel berjalan, dan pengaturan sauna.
\end{abstract}

Kata kunci: Diversivikasi produk, Efisiensi Bisnis, Green Hotel

\section{ABSTRACT}

Abstract- The impact of Covid 19 felt in the hospitality sector forced the hotel to save energy and costs. This study aims to determine product diversification and business efficiency in the sustainability of green hotels in the new normal era at Hyatt Regency Yogyakarta. This study uses qualitative methods with data collection techniques of observation, interviews, documentation and literature study. The sustainability of the green hotel at Hyatt Regency is carried out by product diversification and business efficiency. Product diversification at Hyatt Regency is Designing a working space (Work From Hyatt), Summer camp for children, walk the dog, selling swimming polls for guests outside the Hyatt. The product diversification is carried out with the condition that it is mandatory to consume food or beverage at the Hyatt Hotel at least Rp. 100,000 per participant, Collaborating with grab wheels, the concept of angkringan that is hygienic, healthy, cheap

ISSN: 2355-6587, e-ISSN: 2528-2220

http://ejournal.bsi.ac.id/ejurnal/index.php/jp 
and delicious, and conducts business efficiency by saving electrical energy without reducing service to guests by directing the room electricity with a key chain, so that if guests take key cards most of the the electricity of the equipment will turn off automatically, directing the dispenser of all back office areas to the light switch, so that when turning off the office lights it will automatically turn off the dispenser, minimizing paper use and using recycled paper, building awareness for energy saving programs through posters and campaigns, using ecowasher for toilets, using LED lights, using digital thermostats, installing timers for lighting public areas, installing automatic water tabs in employee dining rooms, installing timers for wastewater treatment plants, using topside LPG Bulk gas, installing arduino to regulate portal water pumps buzzer running, and sauna setting.

Keywords: Product diversification, Business Efficiency, Green Hotel

\section{PENDAHULUAN}

Covid 19 yang menjadi wabah
telah menciptakan kondisi yang berdampak pada kehidupan semua negara. Sector pariwisata mengalami dampak yang luar biasa dikarenakan perjalanan di beberapa negara dan wilayah menjadi terhenti (Baum dan Nguyen, 2019). Akibat pandemic ini masyarakat dihimbau untuk tinggal di rumah, bekerja, sekolah hingga beribadah dari rumah. Industry perhotelan akan bertahan dan bangkit Kembali dengan memperhatikan protokol Kesehatan. Kebiasaan dan perilaku baru berbasis pada adaptasi untuk membudayakan perilaku hidup bersih dan sehat inilah yang kemudian disebut New Normal. Cara yang dilakukan yaitu dengan rutin cuci tangan pakai sabun, pakai masker saat keluar rumah, jaga jarak aman dan menghindari kerumunan. Perubahan ekstrem ini telah memberi dampak yang sangat besar bagi kehidupan masyarakat, serta bagi banyak sektor.

Dampak Covid 19 yang begitu besar dirasakan dibidang perhotelan memaksa pihak hotel untuk melakukan hemat energi dan biaya. Hotel mengolah limbah menjadi bermanfaat. Menurut Graci and Kuehnel dalam Setiawati (2014). Rata-rata hotel menghasilkan 160-200 kilogram CO2 per meter per kamar di setiap lantainya setiap tahun. Selain itu, penggunaan air per tamu per malam rata-rata 170-440 liter (pada hotel berbintang lima). Limbah padat yang dihasilkan pun cukup banyak, yaitu rata- rata 1 kilogram per tamu per malam. Menurut hasil kalkulasi The U.S. Environmental Protec-tion Agency, selama semalam setiap kamar hotel ratarata menghasilkan 29,53 kilogram $\mathrm{CO} 2$ secara rata-rata hotel. Untuk hotel berbintang menghasilkan 33,38 kilogram CO2 per kamar per harinya Hasil studi PBB menunjukkan bahwa industri hotel berkontri-busi lebih dari 5\% terhadap emisi gas $\mathrm{CO} 2$ secara global. Menyadari hal tersebut di atas, maka diperlukan sebuah penerapan operasional pada hotel yang dikenal sebagai hotel berwawasan ramah lingkungan/eco-friendly hotel (Webster, 2006). Menurut Sloan et al. (2013) dampak yang ditimbulkan oleh operasional hotel seperti polusi, limbah, emisi, efek rumah kaca dan karbon dioksida (CO2).

Dunia perhotelan diharapkan akan bangkit di era new Normal sebagai keberlanjutan pariwisata. Pembangunan berkelanjutan menitik beratkan pada aspek ekonomi, lingkungan dan sosial. Menurut Sharpley (2000: 2) konsep pembangunan berkelanjutan (sustainable development) merupakan kolaborasi dari kata inggris " development" (pembangunan) dan, "sustainability (berkelanjutan). Salah satu pihak yang memberikan rumusan konseptual tentanghal itu adalah World Commisions for Environmental and Development (WCED) dimana pembangunan berkelanjutan adalah pembangunan yang menjamin pemenuhan kebutuhan setiap generasi

ISSN: 2355-6587, e-ISSN: 2528-2220

http://ejournal.bsi.ac.id/ejurnal/index.php/jp 
dengan tanpa mengorbankan generasi selanjutnya. Sebagai wujud komitmen terhadap tujuan pembangunan berkelanjutan/ sustainable Development Goals (SDGs), kementerian pariwisata mewujudkannya dalam bentuk apresiasi pengelola hotel yang menerapkan prinsip-prinsip hotel berwawasan lingkungan. Peserta Green Hotel adalah hotel bintang 4 dan bintang 5. Dalam model pariwisata berkelanjutan diusulkan untuk menetapkan tiga dimensi perencanaan: ekonomi, sosial dan lingkungan.

Green Hotel adalah alternatif yang dikenal sebagai "berkelanjutan," "ramah lingkungan" atau "ramah lingkungan" properti (Pizam, 2009). Green Hotel berorientasi alam yang menggunakan metode non-konvensional dan berusaha untuk mengurangi dampak negatif terhadap lingkungan (Han et al., 2010). Menurut Green Hotel Association (2009), Green Hotel atau Hotel ramah lingkungan adalah properti penginapan yang menggabungkan dan mengikuti program dan praktik suara lingkungan seperti penghematan energi dan air, pengurangan limbah, daur ulang untuk mendukung perlindungan lingkungan kita dan mengurangi biaya operasional. Berbeda dengan hotel konvensional yang menyebabkan kerugian yang lebih besar terhadap lingkungan dengan konsumsi berlebihan sumber daya yang langka (yaitu air, energi, dan tanah), Hotel hijau secara sukarela mengikuti standar lingkungan dan pedoman dan menggabungkan dalam membuat keputusan (Han \& Kim, 2010). Konservasi energi, daur ulang, handuk dan program digunakan kembali linen, bola lampu hemat energi, baik terlatih dan berpendidikan karyawan tentang praktik ramah lingkungan, makanan organik dalam menu, keranjang sampah di kamar tamu dan lobi (GHA, 2009)

Menurut Menteri Pariwisata dan Ekonomi Kreatif (Menparekraf) green hotel adalah hotel yang menerapkan kepedulian terhadap lingkungan dan pembangunan pariwisata yang berkelanjutan. Terdapat tiga alasan mendasar untuk menerapkan green hotel pada industri pariwisata di Indonesia yaitu industri pariwisata seperti hotel bisa turut serta dalam bahaya perubahan iklim akibat pemanasan global dengan mengurangi emisi karbon, menghemat energi, konservasi air, dan menggunakan bahan ramah lingkungan, hotel yang menghemat energi seperti listrik, air, dan bahan bakar rupanya bertujuan untuk penghematan pada biaya pengeluaran oprasional hotel, tuntutan dari masyarakat agar para pelaku usaha berperan serta dalam penghematan energi dan kepedulian lingkungan. Terdapat 10 kriteria penilai dalam green hotel yang meliputi, tata guna lahan, penggunaan energi, konservasi air, material ramah lingkungan, kualitas udara, pengelolaan limbah, green purchasing, hotel management, food management dan corporate sosial responsibility (CSR). Dalam Asean Tourism Standards, pengertian green hotel yaitu merupakan hotel yang ramah terhadap lingkungan dan menggunakan energi yang dapat diperbaharui. Adapun kriteria yang menjadikan hotel tersebut disebut 'green' yaitu dalam tahap operasional dan pemeliharaan berpijak pada strategi yang ramah terhadap lingkungan. menggunakan produk yang ramah terhadap lingkungan, adanya kepedulian pihak hotel terhadap masyarakat sekitar, sumber daya manusia yang mengerti dan peduli terhadap lingkungan, managemen pengolahan sampah, efisiensi energi, efisiensi air, kualitas udara dalam ruangan, kontrol kebisingan, pengolahan air limbah, penggunaan bahan yang tidak beracun (Peraturan Menteri Pariwisata, 2013). Dari penjelasan diatas penulis dapat menyimpulkan bahwa green hotel adalah suatu rancangan hotel yang mensinergikan sektor pariwisata dan ekologi secara sejalan dengan konsep arsitektur hijau dengan mengutamakan efisiensi energi. Dalam upaya memenuhi kebutuhan antar generasi itu, terdapat empat hal yang harus diperhatikan, pertama kemampuan dan daya dukung 
ekosistem terhadap pemenuhan kebutuhan, kedua kemampuan melindungi dan melanjutkan kualitas kehidupan, ketiga jaminan dukungan sumberdaya (manusia dan alam) dimasa mendatang, keempat sinergitas kebutuhan antar generasi secara berkelanjutan ( Baiquni, 2001: 35).

Hyatt Regency merupakan salah satu hotel yang menjalankan green hotel. Melalui kegiatan green hotel, Hyatt Regency Yogyakarta berusaha menjalankan komitmen berkelanjutan pada saat pandemic covid 19, penghematan energi menjadi salah satu concern utama perhotelan supaya bisa untuk menutup biaya pelaksanaan protokol Kesehatan. Adanya pandemi Covid 19 ini membuat manajemen harus melakukan inovasi diversivikasi produk agar pendapatan hotel dapat tercapai. Dari uraian tersebut dapat ditarik rumusan masalah bagaimana diversivikasi produk dan efisiensi bisnis dalam keberlanjutan green hotel pada era New Normal di Hyatt Regency.

\section{KAJIAN LITERATUR}

Industri perhotelan merupakan penggerak industri pariwisata dalam penyerapan tenaga kerja dan penghasil ekonomi, namun industry hotel merupakan pengguna energi yang paling besar sehingga hotel sangat perlu untuk mempertimbangkan pembangunan program (sustainability). Hotel yang dapat menghemat energi dan ramah lingkungan disebut green hotel.

Menurut Steven Buerkle dalam Singh (2012) manfaat yang didapatkan oleh perusahaan Ketika menggunakan energi yang ramah lingkungan adalah (a) tidak ada polusi, gangguan, dan bagian yang terbuang; (b) dapat memanfaatkan cahaya matahari yang selalu ada; (c) teknologi ramah lingkungan yang digunakan akan terbukti dapat bertahan hingga 30 tahun: (d) mendapatkan tenaga listrik yang tinggi dengan biaya yang rendah; (e) Tidak ada resiko dari bahan bakar, baik harga maupun suplainya; (f) berkomitmen kepada lingkungan; (g) menggunakan sumberdaya lokal yang otomatis mengurangi penggunaan bahan bakar fosil yang diimpor ; (h) Panel Surya memiliki garansi selama 25 tahun dan dapat bertahan hingga 35 tahun. Singh (2012) menguraikan langkah-langkah yang dapat dilakukan oleh perusahaan untuk menjadi perusahaan hijau, yaitupertama, daur ulang. Perusahaan dapat memulainya dengan mendaur ulang sampah dari berbagai proses pembuangan dari beberapa jenis sisa bahan seperti alumunium, kertas, plastik, dan sampah. Benda-benda tersebut awalnya harus dipisahkan untuk memastikan agar mereka tidak tercampur dan agar bisa terdaur dengan baik. Selain itu bahan sisa tadi tidak dikirimkan ke tempat yang tidak bisa terurai dengan baik. Pekerja juga tidak diperbolehkan memiliki tempat sampah sekitar meja kerjanya karena hal itu akan menghambat pemisahan sampah. Kedua, Mengurangi hasil cetak. Cara lain untuk mengurangi bahan sisa adalah dengan mengirimkan dokumen melalui email daripada mencetaknya, kecuali dokumen tersebut memang harus dicetak dengan kertas. Ketiga, mematikan lampu. Sebuah gedung seharusnya bisa menerima banyak cahaya dengan cara membuka jendela mereka dan membiarkan cahaya matahari masuk daripada menyalakan lampu. Ini tidak hanya berdampak pada pengurangan biaya akan tetapi juga menghemat energi. Menggunakan lampu hemat energi juga menjadi sebuah hal yang bijak yang menggunakan tenaga listrik kurang dari $75 \%$. Keempat; mengurangi menggunakan bahan bakar hasil fosil. Hal ini dirasa penting bagi pelaku bisnis untuk mengurangi bahan bakar yang mereka gunakan. Menciptakan sebuah program untuk bepergian bersamasama akan mengurangi penggunaan bahan bakar fosil selanjutnya perusahaan dapat membuat kemasan yang lebih ramping agar dapat memaksimalkan dari kendaraan yang digunakan sehingga dapat meminimalisir penggunaan emisi. 
Kelima, menggunakan energi terbarukan. Cara lain yang dapat dilakukan perusahaan untuk menghemat energi fosil adalah dengan cara menemukan pilihan energi terbarukan untuk pembangunan perusahaan. Mereka seharusnya dapat memiliki alternative lain untuk mengurangi energi yang mereka gunakan. Penggunaan tenaga surya adalah cara yang tepat untuk mengurangi emisi dan hal tersebut akan membantu perusahaan dalam aspek ekonomi. Keenam, menggunakan produk ramah lingkungan. Banyak perusahaan membuat produknya menjadi lebih ramah lingkungan.

Menurut ASEAN Tourism standar, Green Hotel adalah hotel yang ramah lingkungan dan mempraktekkan penghematan energi. Sebuah hotel dikatakan sebagai green hotel jika memenuhi kriteria (1) kebijakan dan praktek lingkungan dalam operasional hotel, (2) penggunaan green products, (3) bekerjasama dengan organisasi dan masyarakat local, (4) pengembangan human resources, (5) pengelolaan limbah padat, (5) Efisiensi energi, (6) efisiensi air, (7) pengelolaan kualitas udara (indoor dan outdor), (8) control polusi suara, (9) pengelolaan dan perawatan limbah air, (10) pengelolan zat beracun dan kimia.

Menurut World Tourism Organisation (WTO) pembangunan pariwisata yang berkelanjutan, ditetapkan berdasarkan syarat dan kriteria tertentu, yaitu (1) secara ekologi berkelanjutan, yaitu pembangunan pariwisata tidak menimbulkan efek negative bagi ekosistem setempat. Selain itu, konservasi merupakan kebutuhan yang harus diupayakan untuk melindungi sumber daya alam dan lingkungan dari efek negative kegiatan wisata, (2) secara sosial dapat diterima, yaitu mengacu kepada kemampuan masyarakat local untuk menyerap aktivitas pariwisata tanpa menimbulkan konflik sosial, (3) secara kultural bersifat adaptif, artinya masyarakat local mampu beradaptasi dengan budaya wisatawan yang cukup berbeda (tourist culture), (4) secara ekonomis menguntungkan, artinya keuntungan yang diperoleh dari kegiatan pariwisata dapat meningkatkan kesejahteraan masyarakat.

\section{METODE PENELITIAN}

Pendekatan yang dipergunakan dalam penelitian ini adalah pendekatan kualitatif. Menurut Creswell (2016) metode penelitian kualitatif adalah instrument kunci dalam mengumpulkan data dari berbagai sumber, menganalisis secara induktif dan deduktif. Obyek penelitian adalah hal-hal yang berkaitan dengan diversivikasi produk dan efisiensi bisnis green hotel di Hyatt Regency Yogyakarta. Data yang dikumpulkan dalam penelitan ini adalah data primer, yaitu data diperoleh langsung dari objek penelitian. Data ini meliputi pelaksanaan diversivikasi produk dan efisiensi Hyatt Regency Yogyakarta. Pengumpulan data dalam penelitian ini dilakukan melalui 4 teknik yaitu Wawancara, Observasi, studi pustaka, dan dokumentasi.

\section{PEMBAHASAN}

Sumber daya Manusia (SDM) merupakan asset yang paling penting dalam perhotelan. Kualitas Sumber daya manusia sangat menentukan kesuksesan dan kekuatan setiap perusahaan. Hyatt Regency Yogyakarta mempunyai visi yaitu merupakan hotel resort yang paling di sukai di Yogyakarta yang menyediakan akomodasi yang nyaman dan dioperasikan oleh tim yang dinamis dan professional serta disatukan dalam semangat dan tingkah laku dalam memberikan pelayanan dan poduk yang kontemporer seperti yang diharapkan oleh pengunjung yang cerdas baik dalam bidang bisnis ataupun wisata. Sedangkan misi hotel Hyatt Regency yaitu Hotel Hyatt Regency Yogyakarta akan terus menerus menyediakan produk yang selalu inovatif dan berkualitas tinggi, menarik bagi pengunjung lokal maupun international. Misi Sumber Daya Manusia Hyatt Regency Yogyakarta yaitu Salah satu komponen penting hotel 
missionnya adalah menyediakan lingkungan kerja yang mendorong karyawan untuk dapat melampaui harapan tamu. Untuk mengambil langkah ekstra agar kebutuhan dan keinginan Hyatt International, tamu-tamu dan pemilik hotel dapat terlampaui adalah tanggung jawab manajer untuk dapat menciptakan lingkungan kerja yang luas akan diperkenalkan dan dipertahankan sesuai dengan "Hyatt Initatives and Philoshopies" serta sesuai dengan kebutuhan bisnis. Hal itu dirancang untuk memenuhi harapan dan aspirasi para karyawan untuk mendukung tujuan bisnis hotel. Kemudian fokus training adalah menyediakan standar praktek dan pelayanan yang menjamin kenyamanan, efisiensi yang ramah dan menyenangkan bagi tamu-tamu. Ciri khas istimewa dari tim Hyatt Regency adalah kepekaaan terhadap kebutuhan terdadap para tamu, rasa hormat satu sama lain, keyakinan yang teguh atas "People Philoshopy" dan komitmen atas landasan keramah tamahan Hyatt. Fleksibilitas, penuh inisiatif kerja tim yang sungguh-sungguh dan ketulusan yang hangat akan menjadi sebuah karakter istimewa dari tim. Dalam penerapan visi dan misi green hotel, SDM green hotel dituntut untuk tetap survive di masa pandemic. Upaya dalam keberlanjutan Green Hotel yaitu:

\section{Meningkatkan diversivikasi produk}

Diversivikasi produk yang dijalankan di Hyatt regency yaitu (a) merancang working space (Work From Hyatt), bekerja dari rumah sering kali membuat karyawan kerepotan mengenai susahnya jaringan, fasilitas kantor yang tidak tersedia di rumah serta tingkat konsentrasi yang kurang nyaman. Hyatt Regency menawarkan paket Work From Hyatt untuk pelanggan yang memerlukan tempat yang nyaman untuk bekerja dari rumah karena dampak covid 19, (b) Summer camp untuk anak anak, walk the dog, menjual swimming poll untuk tamu di luar Hyatt. program tersebut dijalankan dengan ketentuan wajib mengkonsumsi food atau beverage di
Hyatt Hotel minimal Rp. 100.000,- per peserta, dan pada kenyataannya peserta melakukan kegiatan tersebut dengan mengajak keluarga sehingga per keluarga bisa mengeluarkan biaya konsumsi lebih dari Rp 100.000,- di restoran Hyatt hotel. hal itu membantu pemasukan karena selama pandemic covid 19 permintaan akan kamar hotel sangat minim.

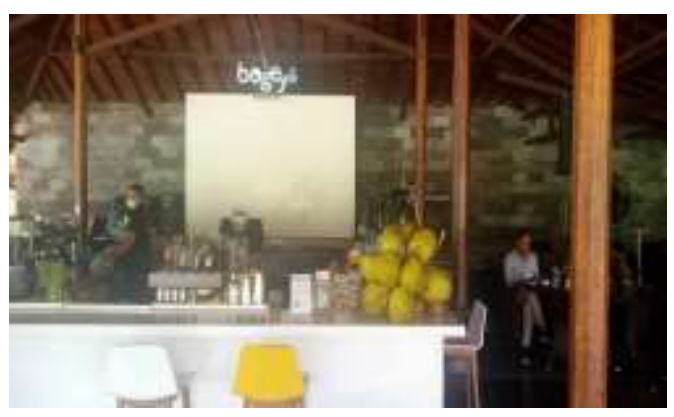

Gambar 1. Bogeys Restoran

Sumber: Dokumentasi Pribadi (2021)

(c) bekerjasma dengan grab wheels, penyewan grab wheels Rp. 10.000,selama 15 menit. Skuter Listrik atau $E$ Scooter Grab Wheels tersebut mirip otopet namun dilengkapi dengan mesin bertenaga baterai yang dapat di-caz ulang selama 5-6 jam ketika malam harinya, berhubung di siang hari dipakai para tamu untuk menyusuri jalur-jalur di kompleks hotel Hyatt Yogyakarta yang memiliki beberapa area Golf Course. Anjuran pemakaian e-scooter Grab Wheels maksimal beban seberat 100 Kilogram, supaya tetap laju jalannya, dan berkemampuan menempuh jarak sejauh 45 Kilometer. Keberadaan e-scooter grab wheels ini membuat tamu bisa lebih meng-eksplor luasan kebun dan tepian lapangan Golf yang ada. Kehadiran 20 unit Grab Wheels untuk tahap pertama, di Hyatt Yogyakarta menjadi fasilitas menarik bagi tamu-tamu hotel yang memiliki area seluas 22 hektar, dikarenakan masih banyak hidden spot yang belum terjamah para tamu in house, yang menginap, maupun tamu member berbagai clubs di Hyatt Jogja. Bagi mereka yang muda dan senang avounturir bisa menjelajahi titik-titik terjauh di berbagai pelosok Hyatt Jogja. 
Adanya fasilitas baru e-scooter grab wheels, kini sangat memungkinkan bagi tamu in house maupun tamu dari luar menyusuri tiap sudut kawasan Hyatt Jogja yang luas. Untuk hotel yang instagramable di semua sudutnya, sangat memungkinkan tamu melakukan foto hunting. mengingat masih banyak tempat-tempat yang belum dilihat tamu Hyatt saking luasnya area. Karena satu lingkaran Jogging Track saja sudah dua kilometer, padahal di Hyatt ada tiga track, hal itu untuk sebagian tamu area itu terlalu jauh, sehingga mereka jalan-jalan hanya disekitar lobby, disekitar pool saja, padahal ketika melintasi jogging track bisa melihat pohon durian yang sedang berbuah, pohon rambutan yang juga sedang berbuah. Dalam hal ini Karyawan/staf juga harus mampu menyampaikan kepada tamu supaya custumer memahami green hotel, seperti tamu diajak ke kebun cabai, kebun sawi, dan memetik buah kelapa. Di kebun itu tamu dipersilahkan untuk memetik hasil kebun di Hotel tersebut. Banyak hal yang tamu belum tahu, sehingga kehadiran Grab Wheels ini memungkinkan tamu melihat-lihat pemandangan yang indahindah itu menjadi experience baru dikala berkunjung ke Yogyakarta.

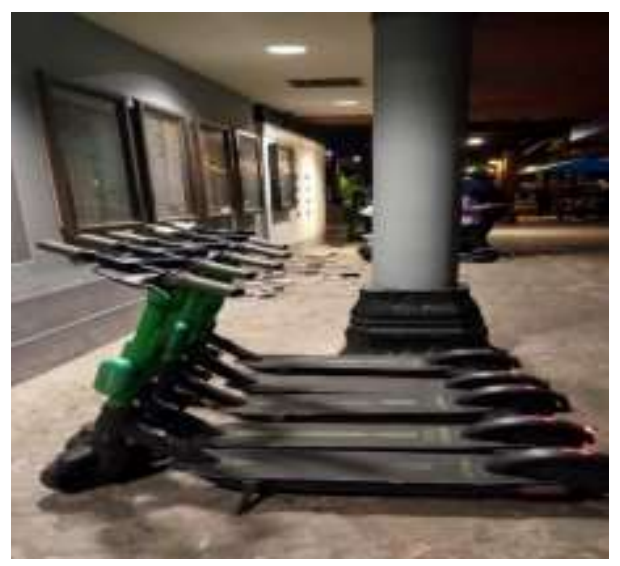

Gambar 2. Grab Wheels

Sumber: dokumentasi pribadi (2021)

(c) Konsep angkringan, kalangan menengah ke atas akan memilih menu angkringan yang higienis, sehat, dengan citarasa yang unik. Maka Hyatt Regency menyediakan angkringan yang higienis, sehat, murah dan enak. Angkringan buka jam 17.00 WIB sampai dengan jam 22.00 WIB. Dengan harga mulai dari Rp. 6.000,-. Angkringan ini dibuka untuk umum. Aturan yang diterapkan di angkringan yaitu (1) wajib mengenakan masker, (2) wajib mengukur suhu tubuh, (3) staf mengenakan masker, (4) staf telah melakukan pengukuran suhu tubuh, (5) staf wajib menyemprotkan disinfektan ke permukaan di antara kunjungan pelanggan.

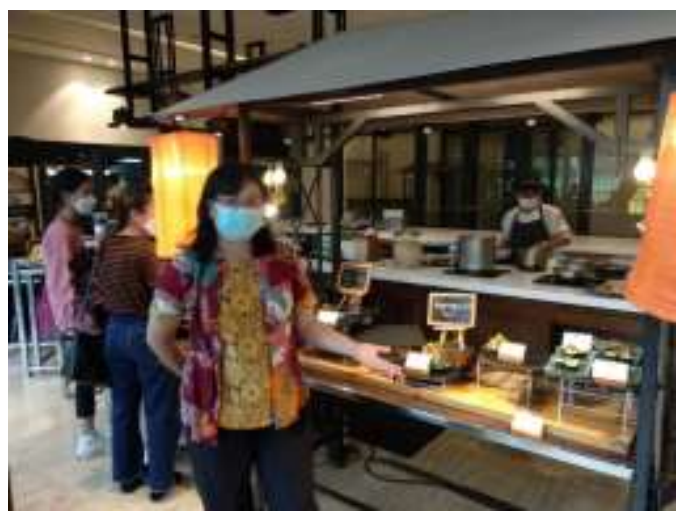

Gambar 3 Angkringan Hyatt

Sumber: dokumentasi pribadi (2021)

Supaya pelanggan mengetahui produk Hyatt Regency, pemasaran dilakukan melalui instagram dan tiktok. Menurut bapak Nurcahyadi General Manager Hyatt Regency Yogyakarta, Jogja dalam kesederhanaannya punya power dan punya energi yang luar biasa untuk bertahan dan untuk menjadi dirinya sendiri, ditengah pandemi yang melumpuhkan semua aktivitas. Jika dibandingkan dengan kota lain, Jogja merupakan kota yang paling cepet recovery-nya. Pada saat hancur, yang lain benar-benar zero, meskipun merayap tapi perlahan Jogja menggeliat bangkit dari keterpurukan. Jogja resilience, punya kemampuan beradaptasi dan tetap teguh dalam situasi sulit, serta punya power untuk survive.

Bisnis hotel yang terdiversifikasi memiliki sejumlah keuntungan dibandingkan hotel yang hanya berfokus pada satu ruang aktivitas jasa hotel. 
Diversifikasi adalah salah satu strategi pengembangan bisnis hotel, yang memungkinkan manajer hotel mencapai tujuannya, menjamin daya-tahan hidup dengan memperoleh tingkat keuntungan yang ditetapkan sampai akhirnya memeroleh posisi dominan dalam pasar jasa hotel. Inilah alasan utama strategi diversifikasi dipilih dalam mendukung keberlanjutan bisnis hotel.

Berdasarkan penelitian, peneliti memahami bahwa selama kondisi ekonomi normal, bisnis Hyatt Regency Yogyakarta sebagai green hotel menjanjikan keuntungan yang sangat besar dan manajemen biasanya mampu menutup besarnya biaya operasional di green hotel. Di era New normal 20202021, tanpa penerapan strategi diversifikasi dan efisiensi bisnis, manajemen Hyatt Regency Yogyakarta menghadapi ancaman kerugian besar di tengah isolasi pariwisata regional, nasional dan internasional, merosotnya jumlah kunjungan tamu wisatawan, rendahnya pendapatan dan melonjaknya biaya operasional bisnis green hotel. Dalam kasus ini, manajemen SDM di Hotel Hyatt Yogyakarta tertantang melaksanakan peran penting untuk mendukung penerapan strategi diversifikasi dan efisiensi bisnis sambil memenuhi komitmen keberlanjutan green hotel di era new normal 2020-2021.

\section{Efisiensi Biaya}

Pada Era New normal, biaya operasional green hotel semakin bertambah. Manajemen hotel harus menambah biaya untuk menyediakan masker gratis untuk tamu, hand sanitizer di public area, ruang meeting, dan ruangan fasilitas tamu. Untuk menutup biaya tersebut, green hotel melakukan penghematan energi. Beberapa program penghematan listrik, dan juga penghematan air yaitu (a) mengarahkan listrik kamar dengan gantungan kunci, sehingga jika tamu mengambil kartu kunci sebagian besar listrik peralatan akan mati secara otomatis kecuali kulkas, 1 soket listrik, dan ruang fcu akan otomatis diatur ke $22^{\prime} \mathrm{C}$ dan blower otomatis disetel ke rendah, (b) mengarahkan dispenser semua area back office ke sakelar lampu, jadi ketika karyawan back office matikan lampu kantor akan otomatis mematikan dispenser, (d) setiap departemen meminimalkan penggunaan kertas dengan mengirimkan semua memo melalui surat elektronik, dan menggunakan kertas daur ulang untuk dicetak, (e) Hyatt Regency Yogyakarta membangun kesadaran untuk program menabung energi melalui poster dan juga kampanye menabung energi, merayakan jam bumi, (f) kamar tamu menggunakan ecowasher untuk toilet, (g) mengganti semua lampu neon di area Back Office menjadi LED, (h) menggantian termostat semua area ke Digital Thermostat. (i) pasang pengatur waktu untuk penerangan area publik, (j) pasang tab air otomatis di ruang makan karyawan. (k) pasang pengatur waktu untuk Instalasi Pengolahan Air Limbah Blower untuk menghindari konsumsi listrik selama puncak waktu muat, (l) menggunakan topside gas LPG Bulk, jadi tidak perlu menggunakan LPG Vaporizor, (m) memasang pengontrol level air digital (Arduino) untuk mengatur pompa air portabel berjalan berdasarkan tingkat air kritis pada waktu beban puncak, (n) sauna yang semula hidup dari jam 05.00 WiB sampai jam 23.00 WIB, dilakukan penghematan dengan menyalakan sauna pada saat tamu datang. Dalam hal ini, SDM di green hotel ini harus mempunyai skill dalam memanage saving energy. Pada akhirnya SDM green hotel di Hyatt bisa menemukan sauna bisa panas setelah dinyalakan hanya dalam waktu 12 menit. Ketika tamu sudah di lobby, staff bagian front office menyalakan tombol sauna pada kamar yang akan digunakan oleh tamu tersebut, sehingga ketika tamu memasuki kamar, sauna sudah panas dan siap digunakan. Pelaksanaan ini dapat menghemat electricity cost sebesar Rp. 90.000.000,- dalam setahun tanpa mengurangi pelayanan ke tamu. 
Dalam industri hotel, jumlah air yang dikonsumsi oleh hotel lebih banyak daripada konsumsi rumah tangga normal. Hal ini berarti bahwa hotel melepaskan banyak air yang sudah tercemar ke alam, sehingga mencemari cadangan air dalam tanah serta memanaskan lingkungan. Dalam menjalankan komitmen keberlanjutan, program penerapan teknologi tepat-guna juga diperlukan agar seluruh hotel mampu mengonsumsi air secara efisien dan meminimalisasi pencemaran dalam penyediaan air. Pemeliharaan air adalah langkah yang perlu diambil hotel untuk mengendalikan dan meminimalisasi limbah cair. Selain itu, banyak hotel semakin mengakui kebutuhan melaksanakan proyek-proyek yang efisien energi dalam sistem pendinginan dan penghangatan ruangan. Dari aspek energi listrik, pencahayaan adalah sistem penggunaan energi terbesar kedua dalam industri hotel. Dalam hal ini, instalasi panel surya pada atap area sauna yang mendukung panasnya sauna dan kolam semakin dilihat sebagai langkah umum untuk menghemat energi dan biaya. Akhirnya, penerapan pengolahan limbah padat pada hotel juga dapat menciptakan penghematan biaya signifikan dalam beban pengolahan limbah sambil menciptakan hotel yang lebih ramah lingkungan.

\section{PENUTUP}

Diversivikasi produk, untuk keberlangsungan Hyatt Regency yaitu dengan (a) merancang working space (Work From Hyatt). Hyatt Regency menawarkan paket Work From Hyatt untuk pelanggan yang memerlukan tempat yang nyaman untuk bekerja dari rumah karena dampak covid 19, (b) Summer camp untuk anak anak, walk the dog, menjual swimming poll untuk tamu di luar Hyatt Regency. Diversivikasi produk tersebut dijalankan dengan ketentuan wajib mengkonsumsi food atau beverage di Hyatt Hotel minimal Rp. 100.000 ,- per peserta. (c) bekerjasma dengan grab wheels, penyewan grab wheels Rp. 10.000,- selama 15 menit, (d) konsep angkringan, karena kalangan menengah ke atas akan memilih jajan angkringan yang sehat, murah dan enak. Untuk menutup tambahan biaya pada saat pandemic Covid 19, green hotel melakukan penghematan energy listrik dan air dengan mengarahkan listrik kamar dari gantungan kunci, sehingga jika tamu mengambil kartu kunci sebagian besar listrik peralatan akan mati secara otomatis kecuali kulkas, 1 soket listrik, dan ruang fcu akan otomatis diatur ke $22^{\prime} \mathrm{C}$ dan blower otomatis disetel ke rendah, mengarahkan dispenser semua area back office ke sakelar lampu, jadi ketika karyawan back office matikan lampu kantor akan otomatis mematikan dispenser, setiap departemen meminimalkan penggunaan kertas dengan mengirimkan semua memo melalui surat elektronik, dan menggunakan kertas daur ulang untuk dicetak, membangun kesadaran untuk program menabung energi melalui poster dan juga kampanye, menggunakan ecowasher untuk toilet, menggunakan lampu LED, menggunakan digital Thermostat, memasang pengatur waktu untuk penerangan area publik, memasang tab air otomatis di ruang makan karyawan, memasang pengatur waktu untuk Instalasi Pengolahan Air Limbah, menggunakan topside gas LPG Bulk, memasang pengontrol level air digital (Arduino) untuk mengatur pompa air portabel berjalan, dan pengaturan sauna. Sebagai upaya penghematan energi, tentu saja komunikasi antar karyawan sangat diperlukan.

Penelitian ini hanya terbatas pada diversifikasi produk dan efisiensi bisnis. Selanjutnya dibutuhkan penelitan lanjutan mengenai sustainable green hotel dalam menerapkan strategi efisiensi dan diversivikasi produk ditinjau dari MSDM Hijau.

\section{REFERENSI}

Baiquni, M. (2001). Participatory Rural Appraisal Pendekatan dan Metode Partisipatif Dalam Pengembangan Masyarakat, 
Yayasan Pembangunan Berkelanjutan / YPB, Jakarta.

Baum, W. M. (2017). Understanding behaviorism: Behavior, Culture, and Evalution (Third Edition).

Cresswell J. (2016). Research Design Pendekatan Metode Kualitatif, Kualitatif, dan campuran. Edisi 4 (terjemahan). Pustaka pelajar: Yogyakarta.

Han, H. and Kim, Y. (2010). "An investigation of green hotel customers' decision formation: Developing an extended model of the theory of planned behavior", International Journal of Hospitality Management, Vol 29, No 4, pp.659-668.

Han, H. and Ryu, K. (2012). "The theory of repurchase decision-making (TRD): Identifying the critical factors in the post-purchase decision-making process", International Journal of Hospitality Management, Vol 31, No 3, pp.786-797.

Moleong, LJ. (2013). Metode Penelitian Kualitatif. Edisi Revisi. Remaja rosda Karya: Bandung.

GHA. (2009), "What are Green Hotels?" Available at: HTTP:// www.greenhotels.com (accessed 12 Nov, 2016).

Peraturan Menteri Pariwisata dan ekonomi Kreatif. Republik

\section{BIODATA PENULIS}

Heni Widyaningsih, S.Pd, M.M, adalah Dosen Akademi Pariwisata Yogyakarta, Program Study Perhotelan.
Indonesia, nomor PM. 53/HM.001/MPEK/ 2013, Tentang Standar Usaha Hotel. Jakarta : Kementerian Pariwisata dan ekonomi Kreatif Republik Indonesia.

Pizam, A. (2009). "Green Hotels: A fad, ploy or a fact of life?", International Journal of Hospitality Management, Vol 28, No 1, p.1.

Setiawati, CI. (2014). Model Hotel Berwawasan Ramah Lingkungan. Banking and Management Review. Vol.3 (20). 378-391.

Singh. P. B, Kamal K. Pandey . (2012) .Greenmarketing:Policiesandpr actices For Sustainabledevelopment. Journal Of Management. Volume 5, No. 1pp 22-30

Sloan, P. Legrand, Willy and Chen, Joseph S. (2013). Sustainability in the Hospitality Industry: Principles Sustainable Operations, (2nd Edition). New York: Routledge.

Webster, K. (2006). Environmental Management in the Hospital Industry: A Guide for Students and Managers. London, UK: Thomson Learning

Hery Krestanto, S.Pd., M.M, adalah Dosen Akademi Pariwisata Yogyakarta, Program Study Perhotelan.

T. Prasetyo Hadi Atmoko, SE., M.M, adalah Dosen Akademi Pariwisata Yogyakarta, Program Study Perhotelan. 